\title{
Posttraumatic bronchobiliary fistulae due to foreign body remnants after a road traffic injury: a case report
}

Seyed-ahmad Seyed-alagheband ${ }^{1}$, Mohammad-kazem Shahmoradi ${ }^{1}$ and Ramin Shekouhi ${ }^{{ }^{*}}$

\begin{abstract}
Background: Bronchobiliary fistula is an extremely rare disease that involves abnormal communication between a hepatic segment and bronchial tree. It is mostly caused by untreated hydatid cyst, liver abscess, iatrogenic stenosis, and, rarely, trauma.
\end{abstract}

Case presentation: We experienced an extremely rare case of bronchobiliary fistula after motor vehicle accident. A 15-year-old Persian boy visited our clinic with chief complaints of persistent pleuritic chest pain, productive cough, weight loss, and fever for 2 months. Coronavirus disease 2019 reverse transcription polymerase chain reaction test was negative. Chest X-ray revealed hazy opacification of right lower lobe. Bronchoalveolar lavage for acid-fast bacillus came back negative. Thoracoabdominal computed tomography scan revealed a collection in segment VIII of the liver communicating with another $13 \times 5 \mathrm{~cm}$ multiloculated collection in the lower lobe of the right lung, with air foci within the collection. Right posterolateral thoracotomy was performed with the impression of bronchobiliary fistula. Drainage of hepatic collection with debridement, diaphragmatic repair, and open decortication of lung followed by resection of the involved segment of the right lung was performed. Histopathologic evaluations revealed abscess formation in pulmonary tissue, and many multinucleated giant cells were seen that appear to be due to foreign body remnants after previous laparotomy surgery. The foreign body seemed to be the remnants of Surgicel absorbable hemostat.

Conclusions: Herein, we report an extremely rare case of a posttraumatic bronchobiliary fistula caused by remnants of Surgicel hemostatic agent. Bronchobiliary fistula is mainly caused by untreated hydatid cyst, liver abscess, iatrogenic stenosis, and, rarely, trauma. Migration and erosion of oxidized regenerated cellulose through the diaphragm seems to be the causative factor of bronchobiliary fistula in this patient.

Keywords: Posttraumatic, Bronchobiliary fistulae, Hepatobiliary fistulae, Case report

\section{Introduction}

Bronchobiliary fistula (BBF) is an extremely rare disease first introduced by Peacock in 1850 [1]. BBF is an abnormal communication between a hepatic segment and bronchial tree. It is mostly caused by untreated hydatid

\footnotetext{
*Correspondence: shekouhi.ramin@gmail.com

${ }^{2}$ Colorectal Research Center, Department of Surgery, Shiraz University

of Medical Sciences, Zand Avenue, P.O. Box 71345-1744, Shiraz, Iran

Full list of author information is available at the end of the article
}

cyst, liver abscess, iatrogenic stenosis, and, rarely, trauma [2]. Herein, we describe a rare case of BBF after motor vehicle accident (MVA) and blunt abdominal trauma. Our patient differs in that the BBF seems to be caused by remnants of nonabsorbed Surgicel (an absorbable hemostatic agent) particles in the abdominal cavity after laparotomy surgery. original author(s) and the source, provide a link to the Creative Commons licence, and indicate if changes were made. The images or other third party material in this article are included in the article's Creative Commons licence, unless indicated otherwise in a credit line to the material. If material is not included in the article's Creative Commons licence and your intended use is not permitted by statutory regulation or exceeds the permitted use, you will need to obtain permission directly from the copyright holder. To view a copy of this licence, visit http://creativecommons.org/licenses/by/4.0/. The Creative Commons Public Domain Dedication waiver (http://creativeco mmons.org/publicdomain/zero/1.0/) applies to the data made available in this article, unless otherwise stated in a credit line to the data. 


\section{Case presentation}

A 15-year-old Persian boy was involved in a car accident 3 months prior. He underwent chest tube insertion owing to massive right-sided pneumothorax. The patient was taken to operation room (OR) for exploratory laparotomy for blunt trauma of abdomen. Surgery revealed a grade 3 liver laceration in segments VI-VII with massive hemoperitoneum. Pringle maneuver was performed to reduce bleeding from the liver. Furthermore, the laceration in segment VI was repaired with deep mattress sutures. However, the surgical team used an absorbable hemostatic agent (Surgicel) in the liver VII segment owing to severe liver contusion caused by blunt trauma to the abdomen. The Surgicel was placed in the anterior part of the liver VII segment, definitive hepatic repair was performed, and he was discharged 10 days later. However, the patient was referred to the clinic with complaints of persistent pleuritic chest pain, productive cough, weight loss, and fever for the last 2 months.

Upon arrival, the patient was hemodynamically stable without signs of respiratory distress. Past medical history was unremarkable except for the recent surgery due to MVA. Family history was unremarkable. Physical examination revealed mild right upper quadrant (RUQ) tenderness at site of previous surgery. Lung auscultation showed decreased breath sounds at the base of right lung. Laboratory data showed leukocytosis (WBC count 14,000) with marked elevation in the neutrophil count, and high C- reactive protein (CRP) levels. Coronavirus disease 2019 (COVID-19) reverse transcription polymerase chain reaction (RT-PCR) test was negative. Chest X-ray revealed hazy opacification of the right lower lobe. Bronchoalveolar lavage (BAL) for acid-fast bacillus (AFB) came back negative. Thoracoabdominal computed tomography $(\mathrm{CT})$ scan revealed a collection in segment VIII of the liver communicating with another $13 \times 5 \mathrm{~cm}$ multiloculated collection in the lower lobe of the right lung, with air foci within the collection (Fig. 1). After thoracoabdominal CT scan, sputum analysis was performed with suspicion of BBF. However, there was no sign of bile in the sputum.

\section{Treatment}

The patient was scheduled for thoracotomy, and preoperative management was considered.

The surgery was conducted under general anesthesia. The patient was scheduled for thoracotomy with the purpose of complete drainage of lung abscess and resection of involved segments. In addition, a transdiaphragmatic approach was carried out for drainage of liver collection (Fig. 2). Diffuse pleural thickening and parenchymal adhesion bands with collection formation were revealed during the operation. Drainage of hepatic collection with debridement and diaphragmatic repair were done. Furthermore, open decortication of lung followed by resection of involved segment of right lung was performed. Intercostal chest drains were placed. Histopathologic evaluation revealed abscess formation in pulmonary tissue with diffuse fibrosis. Many multinucleated giant cells were seen in most parts of inflamed tissues, which appeared to be due to remnants of nonabsorbed Surgicel (an absorbable hemostatic agent) particles used in previous laparotomy surgery (Figs. 3 and 4).

\section{Outcome and follow-up}

The postoperative course was uneventful without any signs of short-term complications. He had no episodes of cough, fever, and bilioptysis after the surgery. The patient was discharged 4 days after surgery with the abdominal drain. The abdominal drain had $10 \mathrm{~mL}$ output after 1 week. On the second follow-up visit 14 days postoperation, abdominal ultrasound was unremarkable without any collection, and the drain was removed.

\section{Discussion}

Classically, BBF can be divided into congenital and acquired. Congenital BBF (CBBF) mostly presents early in life with poor feeding, bilioptysis, and respiratory distress. It mainly coexists with other biliary tract anomalies [3]. Acquired BBF can be a result of damage to the bronchioles, diaphragm, or biliary tracts [4]. Hydatid cysts have been known to be the main cause of BBF. However, thanks to use of broad-spectrum antibiotics and early detection, incidence has decreased tremendously. Other causes of BBF include subphrenic abscess formation, malignancy, iatrogenic factors, and trauma. Posttraumatic BBF is extremely rare, with few cases reported worldwide [5]. To the best of our knowledge, there are only 20 cases (including this patient) of published posttraumatic BBF in English literature (Table 1). Among a total of 20 patients, $17(85 \%)$ patients were males and the rest were females, with a mean age of 25.0 years. Penetrating injures, mostly by gunshot, were the most common cause of posttraumatic BBF (60\%). Postural intractable cough, bilioptysis (bile in the sputum), fever, and pleuritic chest pain are the usual presentation of BBF [6]. Bilioptysis ranges from mild bile-streak sputum to expectoration of extensive amounts of bile [7].

$\mathrm{BBF}$ can be initially misdiagnosed as acquired pneumonia, making the diagnosis of BBF difficult. In terms of diagnosis, chest X-ray may reveal pleural effusion and lung collapse. CT scan shows any fluid collection, including subphrenic abscess, damage to inferior lobes, and obstructed biliary tracts. Pleural fluid and sputum analysis should be assessed for elevated bilirubin levels; however, it requires a high index of suspicion [8]. Santra 


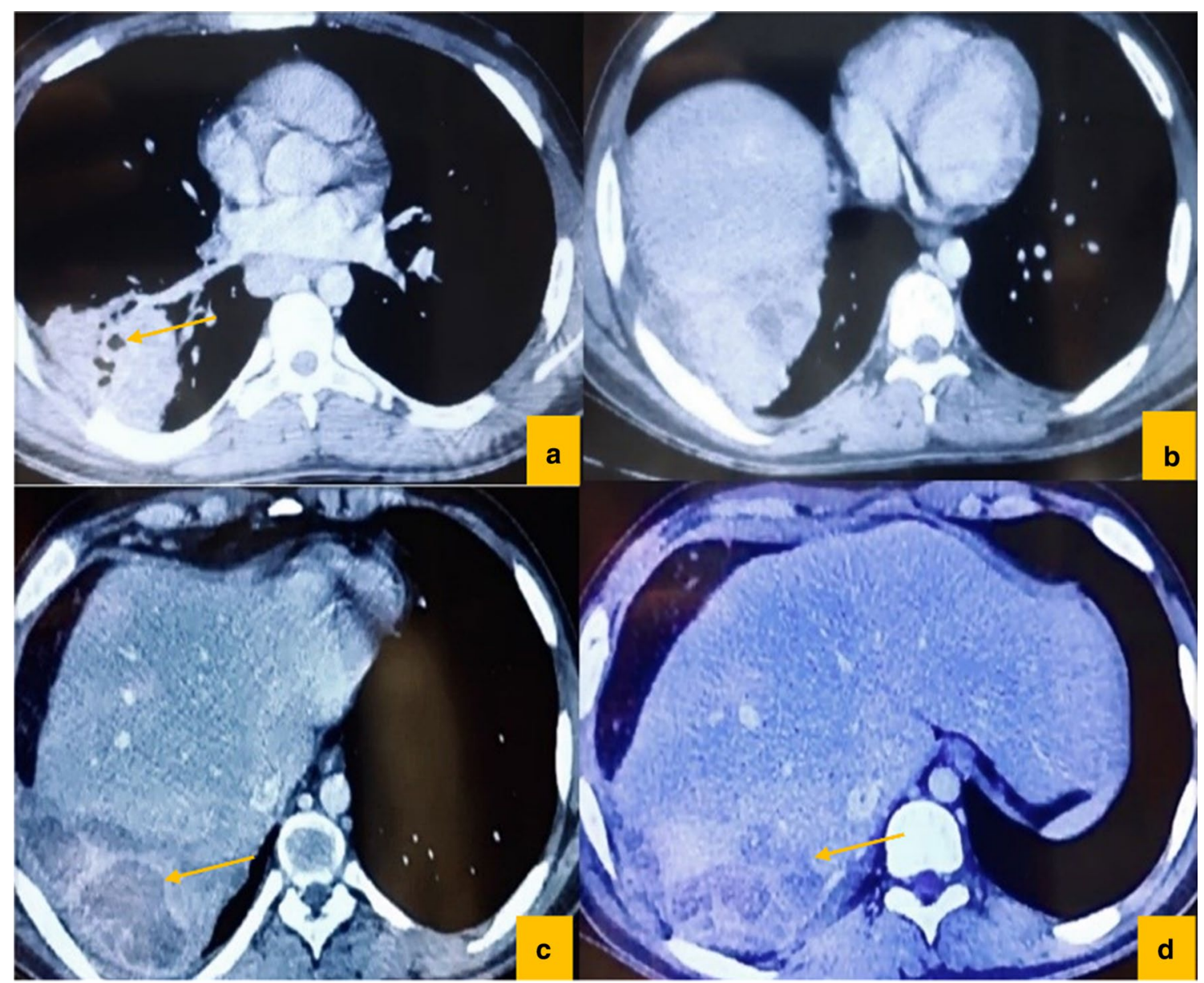

Fig. 1 CT scan of thoracoabdominal region; arrow showing the right lung collection with air foci within the collection (a); arrow indicating the collection in segment VIII of liver (c) and (d)

et al. [9] recommended hepatobiliary iminodiacetic acid (HIDA) scan as a precise noninvasive diagnostic tool for BBF. However, Nigro et al. [10] stated that, owing to reversal of transdiaphragmatic pressure gradient in patients on mechanical ventilation, HIDA scan falls short of confirming the diagnosis.

Magnetic resonance cholangiography (MRCP), ERCP, or percutaneous transhepatic cholangiography (PTCD) are the safest, most precise nonsurgical interventions that can be successfully operated [8]. ERCP is more practical than MRCP because of its capacity to identify the $\mathrm{BBF}$ precisely, and it also has potential for therapeutic interventions [11]. ERCP is considered the first-line treatment in BBF. Traditionally, surgery was the keystone of treatment. However, recently, more conservative, noninvasive treatment methods are preferred initially. Accordingly, among the reports of 20 patients with BBF published in English literature, ERCP was performed in $12(60 \%)$ patients with the goal of complete drainage of hepatic collection. ERCP-guided biliary decompression and stent insertion facilitate bilious drainage into the gastrointestinal tract and successful resolution of BBF. Despite its noninvasive nature, complications including bleeding, cholangitis, pancreatitis, duodenal perforation, and stent occlusion occur. Although ERCP showed success in treatment of BBF, the failure rate of conservative methods alone without surgical interventions was estimated at nearly $38 \%$ [12]. According to previous case reports, death associated with posttraumatic BBF has not been reported.

Open surgery is indicated if conservative techniques fail. Multiple surgical approaches have been recommended for treatment of BBF, including thoracotomy, thoracoabdominal approach, and laparotomy. Most studies preferred the thoracoabdominal approach as the definite surgical method. According to our results, 15 (75\%) patients, underwent thoracotomy for resection of involved lung segment, and fistulectomy (Table 1). It 


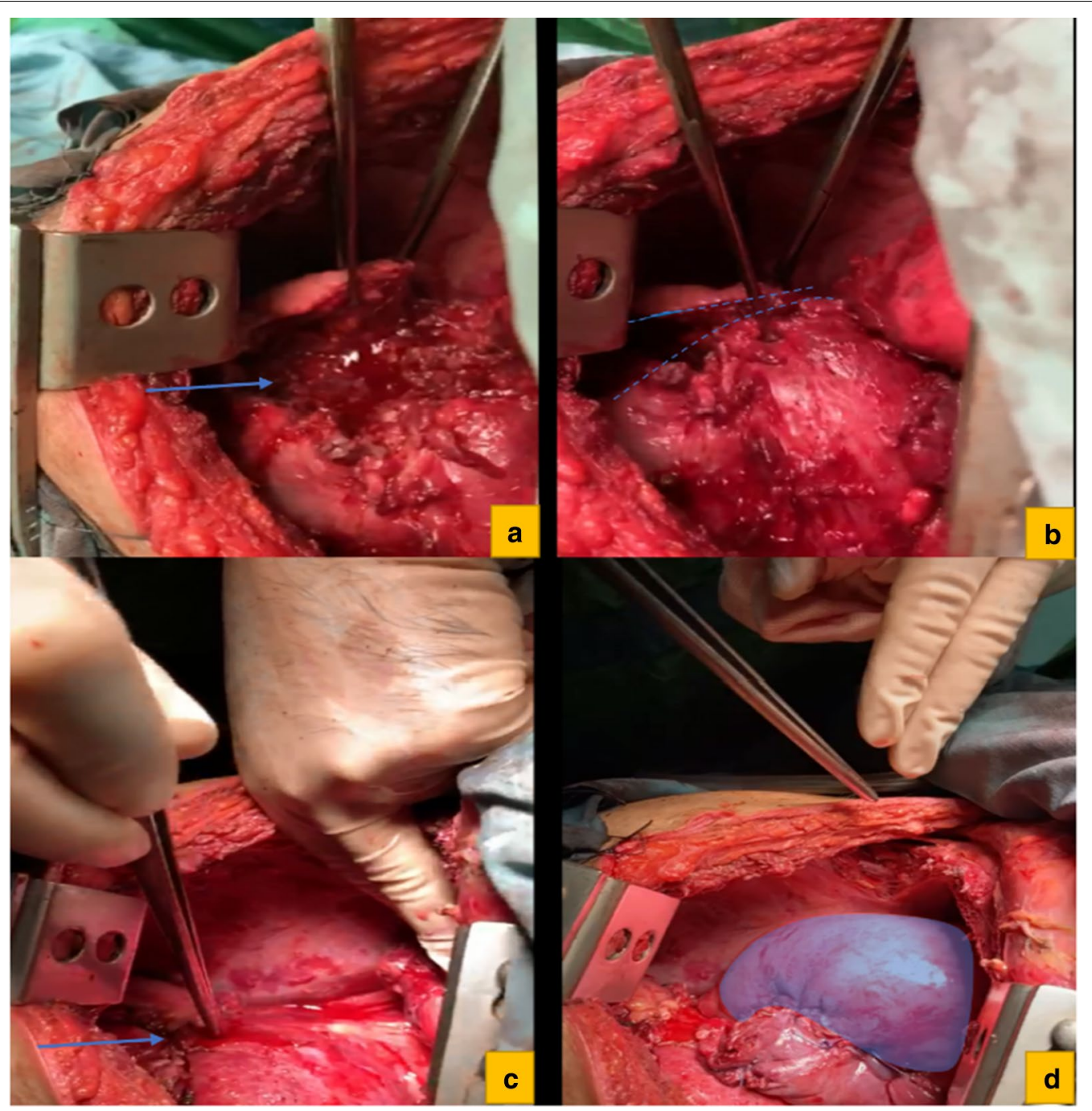

Fig. 2 Right posterolateral thoracotomy, and transdiaphragmatic approach for drainage of liver collection. Ruptured diaphragm due to BBF shown by blue arrow (a); repaired diaphragm after the operation and drainage of liver collection indicated by arrow (c); and lung's right middle lobe after fistulectomy and segmentectomy of involved right lower lobe (d)

provides accessibility to perform decortication, complete excision of fistulae tract, wedge resection of lung parenchyma, lobectomy, and diaphragmatic closure [13, 14]. We considered surgical intervention as the first-line therapy because of the subphrenic abscess and better management of biliary leakage to the abdominal cavity. Our case differs in that the BBF seems to be caused by remnants of nonabsorbed Surgicel particles in the abdominal cavity after laparotomy surgery.

Surgicel, which is a bioabsorbable hemostatic agent, consists of oxidized regenerated cellulose. It is a thrombogenic material mainly used to control bleeding. Once the Surgicel is placed in the surgical bed, it forms a gelatinous mass that helps control the bleeding and clot formation [15]. Macrophage processing seems to play a role in the absorption mechanism of Surgicel in the body; however, the exact mechanism is not well understood. The absorption process of Surgicel by the body begins after 18 hours, and will usually be absorbed within 6 weeks [16]. However, in our case, Surgicel was not completely absorbed after 3 months of insertion, as we noticed remnants of Surgicel on histological evaluation.

Although oxidized cellulose is a safe hemostat, complications including delayed absorption, granuloma formation, and compression effect to surrounding organs still occur. There have been multiple reports of paraplegia following thoracotomy due to compressive effects of oxidized cellulose. Swelling and migration of oxidized 


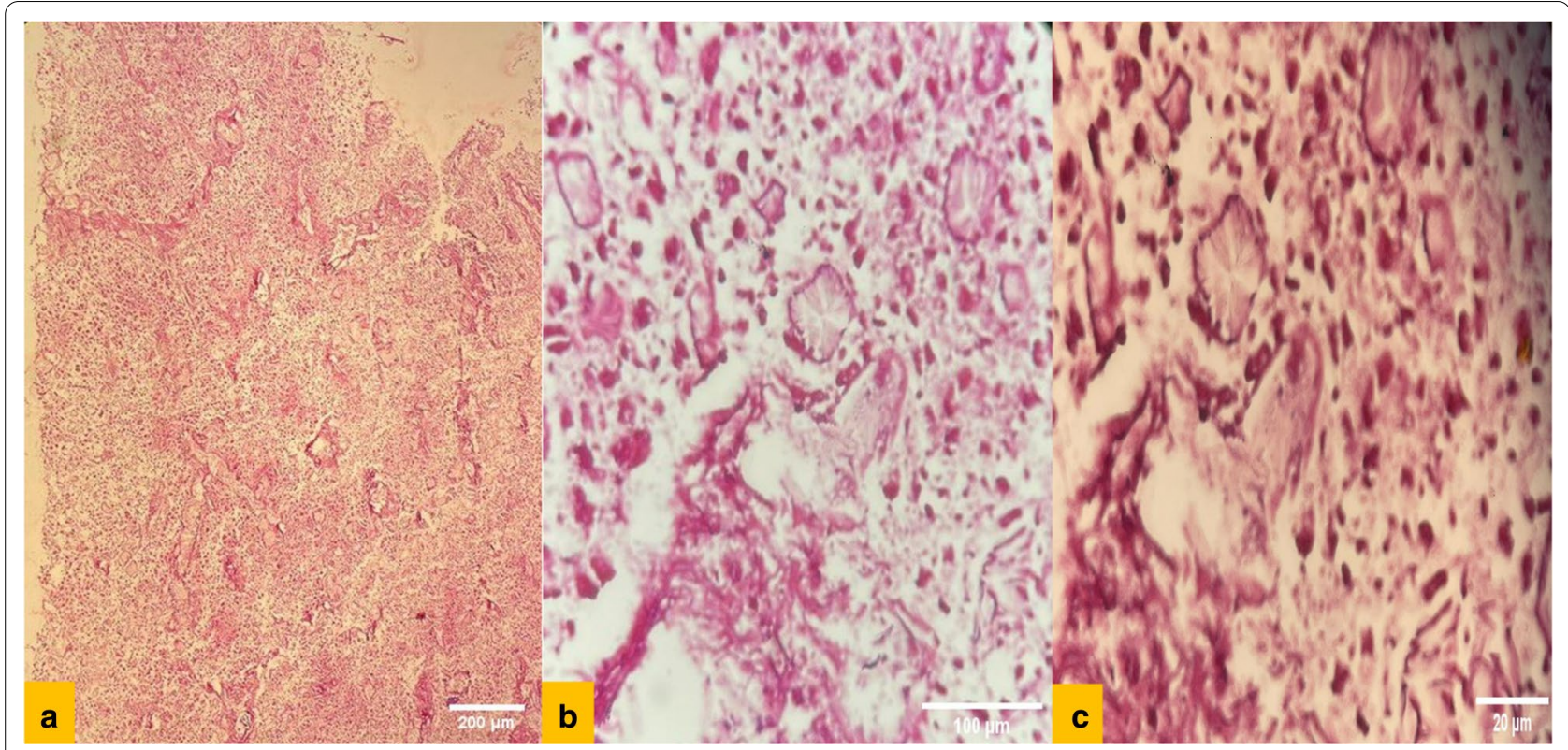

Fig. 3 Histology of nonabsorbed Surgicel particles found in excised specimen of BBF

cellulose through intervertebral foramen into the spinal canal were the main cause of paraplegia following Surgicel insertion after thoracotomy. The pressure gradient between the spinal canal and pleural space seems to be the causative factor for postthoracotomy Surgicel migration [17-20].

In addition, Dokumcu et al. [21] reported a patient of esophageal atresia (EA) with distal tracheoesophageal fistula (TEF) who underwent thoracotomy for surgical management of esophagus and tracheal defects. However, 1 month after thoracotomy, the patient developed symptoms indicative of TEF. Esophagoscopy revealed patent TEF with the nonabsorbed Surgicel in the TEF lumen, which was not removed to prevent fistulae enlargement. Three weeks later, the Surgicel hemostat disappeared and the patient underwent another thoracotomy for closure of TEF. Dokumcu et al. concluded that postoperative Surgicel migration and expansion were the cause of TEF recurrence.

In our case, the major cause of Surgicel migration, and erosion through the diaphragm, seems to be the increased thoracoabdominal pressure gradient (TAPG), which caused the migration of Surgicel to reach the diaphragm, especially in the setting of increased intraabdominal pressure following blunt trauma and laparotomy surgery. That said, our second hypothesis is that the delayed absorption of Surgicel material could have caused an abscess within the involved liver segment, which later on the abscess fistulized to the adjustment diaphragm and lung tissue, causing BBF. Regardless, delayed absorption of Surgicel hemostatic agent seems to be the main cause in the formation of BBF. However, due to rarity of the disease, there is not enough evidence to support any of these hypotheses. To the best of our knowledge, this is the first case of posttraumatic BBF due to remnants of nonabsorbed Surgicel hemostatic agent.

\section{Conclusion}

Herein, we reported an extremely rare case of posttraumatic bronchobiliary fistula (BBF) caused by remnants of Surgicel hemostatic agent. BBF is mainly caused by untreated hydatid cyst, liver abscess, iatrogenic stenosis, and, rarely, trauma. The patient was a 15 -year-old boy who developed BBF following laparotomy surgery, in which Surgicel hemostatic agent was inserted to control bleeding due to liver laceration. Migration and erosion of oxidized regenerated cellulose through the diaphragm seems to be the causative factor of BBF in this patient. We reviewed the early signs and symptoms of BBF, the gold standard diagnostic method, and emphasized the importance of surgical management in the treatment of BBF. 

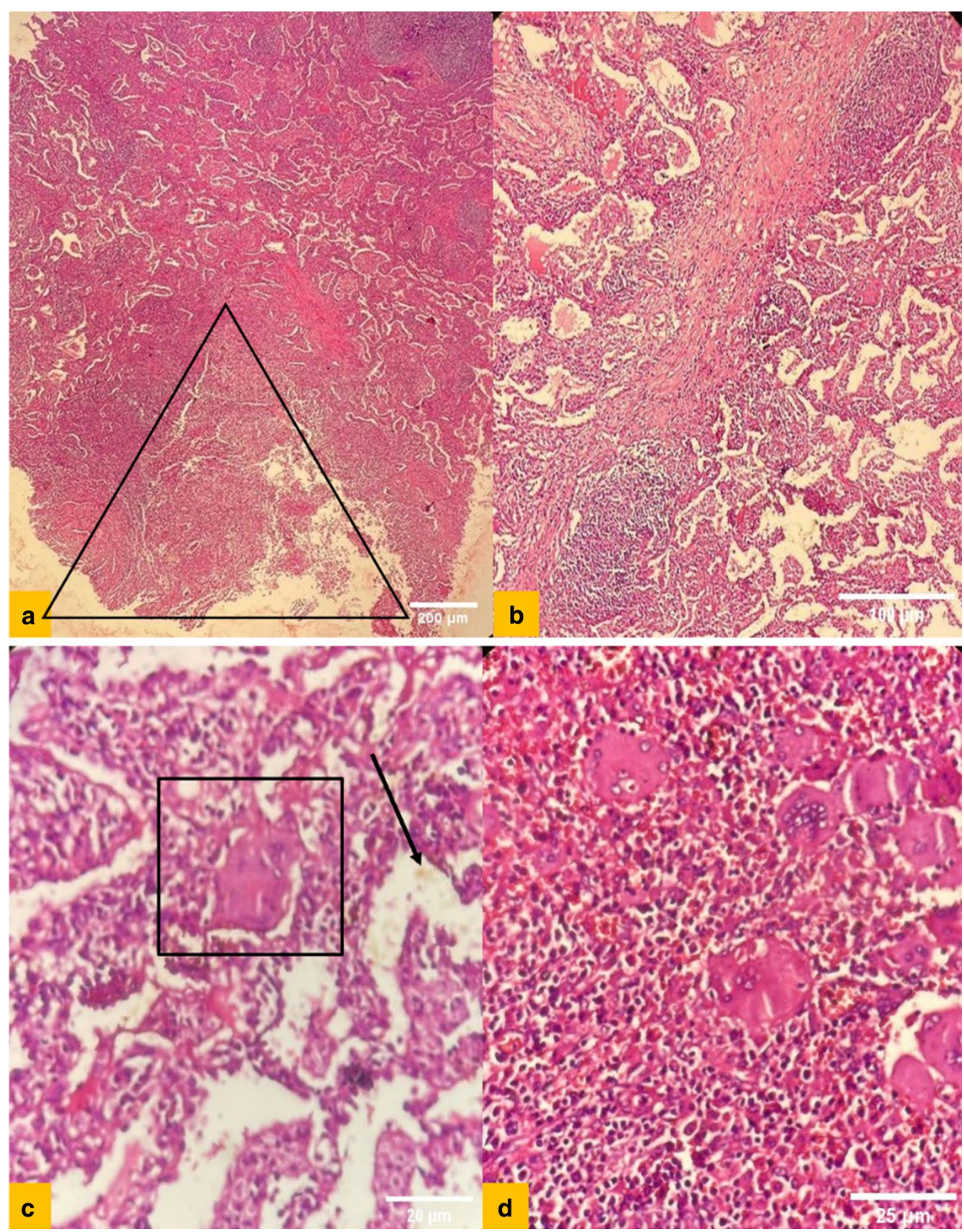

Fig. 4. Histologic evaluation of the specimen; fistulation of BBF into the lung parenchyma $(\times 4)(\mathbf{a})$; diffuse fibrosis in pulmonary tissue $(\times 10)(\mathbf{b})$; giant cell within the involved lung segment with, interestingly, bile staining in the alveoli (black arrow) $(x 40)(\mathbf{c})$; many multinucleated giant cells in most parts of involved liver tissue that appear to be due to foreign body remnants (Surgicel) after previous surgery $(\times 40)(\mathbf{d})$

\section{Patient perspective}

Five months ago, I had an accident and I was rushed to a nearby hospital. I had an operation and was admitted for two weeks. 2 days after I discharged from the hospital, I developed with persistent cough, fever and malaise. First, I thought I was infected with covid-19 due to my recent hospital admission. However, my COVID-19 test came back negative. After a lot of investigations, I was diagnosed with BBF. I underwent a second surgery and I was doing well. All of my symptoms resolved and I am grateful that I can go back to my normal life. 
Table 1 Published cases of BBF

\begin{tabular}{|c|c|c|c|c|c|c|c|}
\hline Year & Age & Sex & Bilioptysis & $\begin{array}{l}\text { Lobe } \\
\text { involvement }\end{array}$ & Mechanism of trauma & Surgery & Survival \\
\hline $1983[22]$ & 29 & $M$ & Yes & Right & Penetrating trauma (gunshot) & Thoracotomy, lobe resection & A \\
\hline $1984[23]$ & 38 & $M$ & Yes & Right & Penetrating trauma (gunshot) & Thoracotomy, lobe resection & A \\
\hline $1994[24]$ & 15 & M & Yes & Right & Penetrating trauma (gunshot) & Thoracotomy & $A$ \\
\hline $2002[25]$ & 26 & $M$ & Yes & NM & NM & Thoracotomy, ERCP & A \\
\hline $2002[25]$ & 42 & $M$ & No & NM & NM & ERCP & A \\
\hline $2002[25]$ & 33 & $M$ & No & NM & NM & $\mathrm{ERCP}$ & $A$ \\
\hline $2007[26]$ & 20 & $M$ & Yes & Right & Penetrating trauma (gunshot) & Thoracotomy, lobe resection & $A$ \\
\hline $2009[9]$ & 18 & $M$ & Yes & Right & Blunt trauma (MVA) & Thoracotomy & A \\
\hline $2009[27]$ & 18 & $\mathrm{~F}$ & Yes & Right & Penetrating trauma (gunshot) & ERCP & A \\
\hline $2009[28]$ & 27 & M & Yes & Right & Penetrating trauma (gunshot) & Thoracotomy & $A$ \\
\hline $2012[8]$ & NM & $M$ & Yes & NM & Penetrating trauma (gunshot) & Thoracotomy, ERCP & $A$ \\
\hline $2012[8]$ & NM & $M$ & NM & NM & Penetrating trauma (stab wound) & Thoracotomy, ERCP & A \\
\hline $2012[8]$ & NM & M & NM & NM & Penetrating trauma (gunshot) & Thoracotomy & $A$ \\
\hline $2012[8]$ & NM & M & NM & NM & Penetrating trauma (gunshot) & Thoracotomy, ERCP & A \\
\hline $2012[8]$ & NM & $\mathrm{F}$ & NM & NM & Penetrating trauma (gunshot) & Thoracotomy, ERCP & A \\
\hline $2012[29]$ & NM & $F$ & Yes & Right & Blunt trauma (MVA) & $\begin{array}{l}\text { Laparotomy, } \\
\text { ERCP, PTC, embolization } \\
\text { of fistula tract, } \\
\text { Thoracotomy } \\
1 \text { year later }\end{array}$ & $A$ \\
\hline $2014[30]$ & 29 & $M$ & Yes & Right & Blunt trauma & $\begin{array}{l}\text { ERCP, stent insertion, fistula blockage with } \\
\text { cyanoacrylate glue and endocoils }\end{array}$ & $A$ \\
\hline 2018 [31] & 18 & $M$ & Yes & Right & Blunt trauma (falling down) & ERCP, stent insertion & $A$ \\
\hline $2020[32]$ & 22 & $M$ & Yes & Right & Penetrating trauma (gunshot) & $\begin{array}{l}\text { Laparotomy, } \\
\text { ERCP, PTC, thoracotomy, fistulectomy, lobe } \\
\text { resection }\end{array}$ & $A$ \\
\hline 2021 (our case) & 15 & M & No & Right & Blunt trauma (MVA) & Thoracotomy, fistulectomy, lobe resection & A \\
\hline
\end{tabular}

$E R C P$, endoscopic retrograde cholangiopancreatogram; PTC, percutaneous transhepatic cholangiography; $M V A$, motor vehicle accident; $A$, alive

\section{Acknowledgements}

Not applicable.

\section{Authors' contributions}

SS-drafted the manuscript and provided images and histologic evaluations; RS - helped with the draft (corresponding author) and reviewed the literature; MS - supervisor, provided initial feedback, and reviewed the final manuscript. The authors read and approved the final manuscript.

\section{Funding}

No funding was obtained for this study.

\section{Availability of data and materials}

All data generated or analyzed during this study are included in this published article.

\section{Declarations}

\section{Ethics approval and consent to participate}

The purpose of this research was completely explained to the patient and parents, and they were assured that their information will be kept confidential by the researchers. Written informed consent was obtained from the patient's parents for publication of this case report and any accompanying images. A copy of the written consent is available for review by the Editor-in-Chief of this journal. The present study was approved by the medical ethics committee of the academy.

\section{Consent for publication}

Written informed consent was obtained from the patients' legal guardians for publication of this case report and any accompanying images. A copy of the written consent is available for review by the Editor-in-Chief of this journal.

\section{Competing interests}

The authors declare that they have no competing interests.

\section{Author details}

${ }^{1}$ Department of Surgery, Lorestan University of Medical Sciences, Lorestan, Iran. ${ }^{2}$ Colorectal Research Center, Department of Surgery, Shiraz University of Medical Sciences, Zand Avenue, P.O. Box 71345-1744, Shiraz, Iran.

Received: 24 January 2021 Accepted: 12 April 2021

Published online: 22 May 2021

References

1. PeacockTB. Case in which hydatids were expectorated, and one of suppuration in a hydatid cyst of the liver communicating with the lungs. Edinburgh Med Surg J. 1850;74(184):33.

2. Nassar Y, Hida S, Richter S. A Biliobronchial fistula in a patient with hepatocellcular carcinoma treated with chemoembolization diagnosed by hepatobiliary iminodiacetic acid scan and managed by endoscopic retrograde cholangiopancreatography. Gastroenterol Res. 2017;10(6):383. 
3. Li T-Y, Zhang Z-B. Congenital bronchobiliary fistula: a case report and review of the literature. World J Clin Cases. 2019;7(7):881.

4. Nathani A, et al. Bronchobiliary fistula caused by diaphragmatic invasion of a hepatic tumour. Case Rep. 2018;2018:224753.

5. Mehrzad H, Aziz A, Mangat K. Novel treatment (new drug/intervention; established drug/procedure in new situation): Transhepatic embolisation of a traumatic broncho-biliary fistula: a novel approach. BMJ Case Rep. 2012;2012:1.

6. Banerjee $\mathrm{N}$, et al. Post-Traumatic bronchobiliary fistula. BMJ Case Reports CP. 2019;12(4):e228294.

7. Guan-qun $L$, et al. A successful treatment of traumatic bronchobiliary fistula by endoscopic retrograde biliary drainage. Chin J Traumatol. 2012;15(1):59-61.

8. Andrade-Alegre R, Ruiz-Valdes M. Traumatic thoracobiliary (pleurobiliary and bronchobiliary) fistula. Asian Cardiovasc Thor Ann. 2013;21(1):43-7.

9. Santra A, et al. Traumatic bronchobiliary fistula diagnosed by99mTcmebrofenin hepatobiliary scintigraphy. Nucl Med Commun. 2009;30(8):652-3.

10. Nigro J, et al. Bullets and biliptysis. Ann Thor Surg. 2002;73(5):1645-7.

11. Rösch T, et al. A prospective comparison of the diagnostic accuracy of ERCP, MRCP, CT, and EUS in biliary strictures. Gastroint EndosC. 2002;55(7):870-6.

12. Oparah SS, Mandal AK. Traumatic thoracobiliary (pleurobiliary and bronchobiliary) fistulas: clinical and review study. J Trauma. 1978;18(7):539-44.

13. Kontoravdis N, Panagiotopoulos N, Lawrence D. The challenging management of hepatopulmonary fistulas. J Thor Dis. 2014;6(9):1336.

14. Tocchi A, et al. Treatment of hydatid bronchobiliary fistulas: 30 years of experience. Liver Int. 2007;27(2):209-14.

15. Kaneyuki D, et al. Surgicel ${ }^{\circledR}$ packing remnants mimicking mediastinitis after adult cardiac surgery. Interactive Cardiovasc Thor Surg. 2018;26(6):1035-6.

16. Liu J, et al. Delayed absorption of oxidized cellulose (Surgicel) in postthyroidectomy patients. J Ultrasound Med. 2016;35(6):1349-51.

17. Brodbelt A, et al. Intraspinal oxidised cellulose (Surgicel) causing delayed paraplegia after thoracotomy-a report of three cases. Ann R Coll Surg Engl. 2002;84(2):97.

18. Dua S, et al. Oxidised regenerated cellulose: an unusual cause of paraplegia following oesophagectomy. Interactive Cardiovasc Thor Surg. 2010;10(5):833-5.
19. Henry MC, et al. Postoperative paraplegia secondary to the use of oxidized cellulose (Surgicel). J Pediatr Surg. 2005;40(4):E9-11.

20. Rustagi T, et al. Oxidized cellulose (Surgicel) causing postoperative Cauda equine syndrome. Cureus. 2017;9:7.

21. Dokumcu Z, et al. Postoperative recurrent tracheoesophageal fistula: an unusual complication of oxidized regenerated cellulose (Surgicel ${ }^{\circledR}$ ). Int J Pediatric Otorhinolaryngol. 2014;78(4):701-3.

22. Coselli JS, Mattox KL. Traumatic bronchobiliary fistula. J Trauma Acute Care Surg. 1983;23(2):161-2.

23. Ivatury RR, O'Shea J, Rohman M. Post-traumatic thoracobiliary fistula. J Trauma Acute Care Surg. 1984;24(5):438-42.

24. Rothberg ML, et al. Traumatic thoracobiliary fistula. Ann Thor Surg. 1994;57(2):472-5.

25. Singh B, et al. Conservative management of thoracobiliary fistula. Ann Thor Surg. 2002;73(4):1088-91.

26. Eryigit $\mathrm{H}$, et al. Management of acquired bronchobiliary fistula: 3 case reports and a literature review. J Cardiothor Surg. 2007;2(1):52.

27. Gandhi N, et al. Bronchobiliary fistula after penetrating thoracoabdominal trauma: case report and literature review. J Trauma Acute Care Surg. 2009;67(5):E143-5.

28. Ball CG, et al. Importance of liver drainage in biliary-bronchopleural fistula resulting from thoracoabdominal gunshot injury. Can J Surg. 2009;52(1):E12.

29. Mehrzad H, Aziz A, Mangat K. Transhepatic embolisation of a traumatic broncho-biliary fistula: a novel approach. Case Rep. 2012;2012:2012006702.

30. Mukkada RJ, et al. Bronchobiliary fistula treated successfully with endoscopic microcoils and glue. Ann Thor Surg. 2014;98(2):e33-4.

31. Jha P, Joshi BD, Jha BK. Hepatic artery pseudoaneurysm, bronchobiliary fistula in a patient with liver trauma. BMC Surg. 2018;18(1):1-4.

32. Coughlin JM, et al. Surgical management of Bronchobiliary fistula after thoracoabdominal trauma. Am Surg. 2020;1:0003134820945263.

\section{Publisher's Note}

Springer Nature remains neutral with regard to jurisdictional claims in published maps and institutional affiliations.
Ready to submit your research? Choose BMC and benefit from:

- fast, convenient online submission

- thorough peer review by experienced researchers in your field

- rapid publication on acceptance

- support for research data, including large and complex data types

- gold Open Access which fosters wider collaboration and increased citations

- maximum visibility for your research: over 100M website views per year

At $\mathrm{BMC}$, research is always in progress.

Learn more biomedcentral.com/submissions 